\title{
Graduation Resources in Medical Case Reports Written by Native and Non-Native Medical Writers
}

\author{
Muna Abdulhussein Swear \\ University Putra Malaysia, Malaysia \\ E-mail:mona_ode@yahoo.com
}

Doi:10.7575/aiac.alls.v.6n.3p.101

Received: 20/01/2014

URL: http://dx.doi.org/10.7575/aiac.alls.v.6n.3p.101

Accepted: 26/03/2015

\begin{abstract}
The Appraisal Theory includes three subsystems of evaluation; Attitude, Engagement, and Graduation. This study focuses on Graduation subsystem which is used by writers to amplify or diminish the scope of these two subsystems. It consists of Focus and Force options. Focus expressions are usually non-gradable they tend to sharpen or soften the utterances. Force, on the other hand modulates gradable expressions; which can be emphasized or downtoned the writer's utterances in terms of Intensification and Quantification. This pilot test is conducted to characterize the Force: Graduation of the heteroglossic resources in 20 MCR written in English by NS and NNS (Malaysian) medical writers. MCR is a medical genre that has proven recently to be very important in the advancement of medical researches and in serving pedagogical purposes to offer a description to the practical strength of the clinical decision-making. Many incidents of Force: Graduation are collected for the purpose of analysis. The analysis includes investigating the gradable heteroglossic resources in the MCRs of both groups of writers and examining the differences in employing these resources. The results indicate a little bit more frequent occurrence in the NS medical writers MCRs gradable heteroglossic expressions compared with those of NNS medical writers. Additionally, the use of these resources in the discussion sections of both groups is higher than in the other sections for both writers.
\end{abstract}

Keywords: graduation resources, appraisal theory, corpus-based research

\section{Introduction}

Evaluation of Language as an interested area of research and investigation is dated back to Labov (1967) and his former fellow Barke (1962), and Labov $(1972,1982,1984,1997)$ whose works were based on narratives. Many other studies also focused on evaluation from theoretical perspectives such as Hoey $(1983,2001)$ and Biber $(2000)$. Other studies focused on evaluation from a systemic-functional perspective like those of Eggins and Slade (1997), Hunston (2000), Hunston and Thompson (2000), Martin (2000, 2002, 2003, 2004), (Martin \& Rose 2003; Martin \& White 2005; White 2004a, 2004b). The aforementioned studies have focused on both spoken and written language in many genres, as a result many frameworks and models come into being (Vien Jr.,Orlando, 2008, p.807-808).

The term "Evaluation" was proposed by Hunston and Thompson (2000) to refer to the expressions used by the writer or speaker to express "attitude or stance towards viewpoints on, or feelings about the entities or propositions that he or she is talking about. .." Evaluation in the text allows the writer or speaker to manipulate, persuade, and/ or hedge the interlocutors (Chang, 2010, p.12).

Evaluation, stance, and appraisal are terms adopted by many scholars to address the interpersonal meaning of language. The interpersonal metafunction is one of three metafunctions of language in the sense of SFL. Interpersonal meanings of language have been codified by scholars in different models and frameworks. For instance, scholars like Hyland discussed two aspects of interpersonal meaning of language "hedge and booster"(1998), and "metadiscourse" (2004a).Then he proposed in (2006) a model of engagement and stance interactional in academic discourse. Biber (2006a) also proposed "Epistemic and attitudinal stance," and finally there is the "appraisal" of Martin (2000), Martin and White (2005), Martin and Rose (2007).

This pilot study is grounded on the Appraisal framework of Martin and White (2005) Figure (1), and specifically on the Graduation subsystem of appraisal Figure (2).The Appraisal describes and explores "the way language is used to evaluate, to adopt stances, to construct textual personas and to manage interpersonal positioning and relationships" (Behnam,2013,p.291). Appraisal system comprises three subsystems and their subcategories are Attitude, Engagement, and Graduation. 


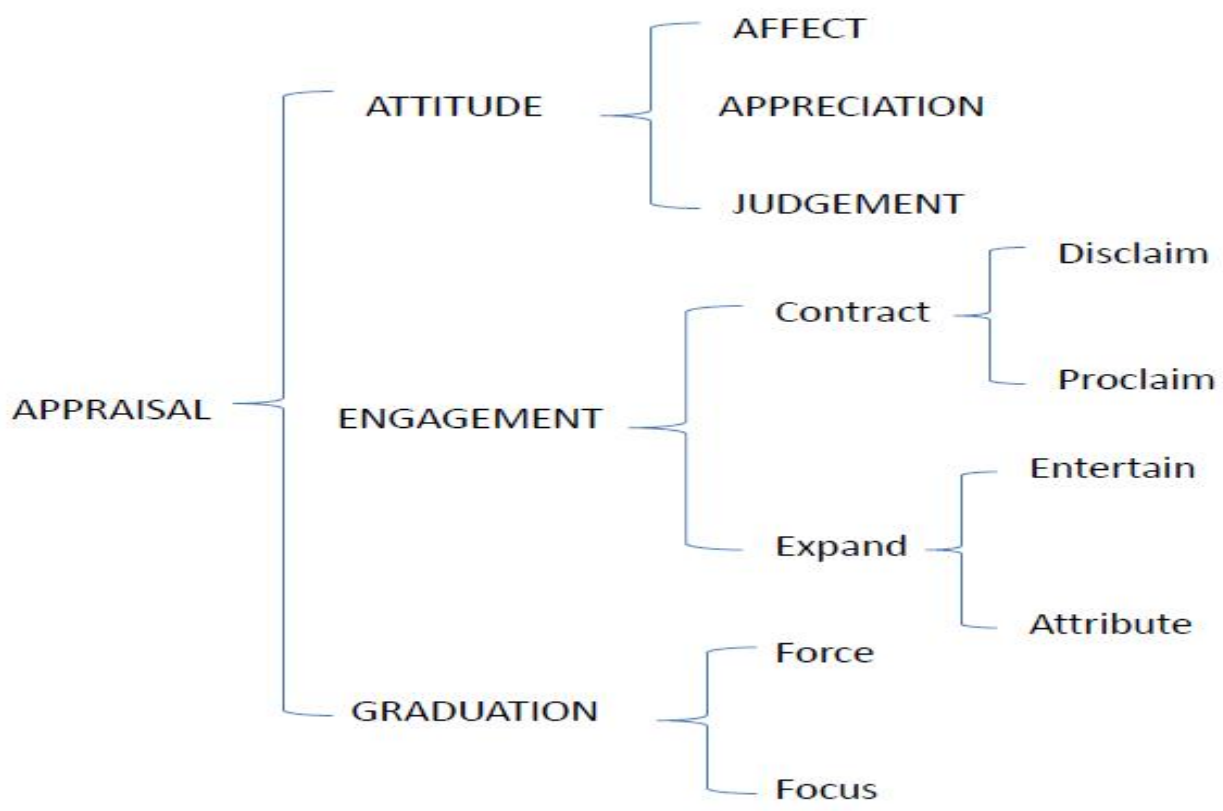

Figure 1. The network of Appraisal (Martin \& White, 2005)

Graduation has been traditionally explored under headings such as intensifiers, amplifiers, and emphatics and classified by scholars like (Martin and Rose, 2003; Droga and Humphrey, 2002; Hood, 2004a, 2004b). However, all frames of Graduation are derived and of slightly differences from White's (1998, 1999) model which was developed for the purpose of analyzing the media news texts (Lee, 2006, p.101).

Graduation (or Amplification) consists of two main categories: Force and Focus. Focus; works to broaden or narrow a particular category membership in terms of two options sharpen or up-scale which indicates the writer's strong position whether positive or negative. These values are indicated gradually more under the headings of booster, amplifiers, and intensifiers, e.g., "he effectively admitted it," and soften or down -scale: characterizing an instance as having a "marginal membership in the category." Instances of this option in literature as hedging and "vague language" are used by the writer to maintain solidarity with interlocutors who anticipated not sharing the same viewpoints, e.g, "a sort of truth"

Force, on the other hand involves the choices of raising or lowering the intensity of gradable items, to adjust the volume of gradable meanings by 'up-scaling' or 'down-scaling' volumes of utterances. The authorial voice up scales the force of the meaning to indicate strong investment to the proposition. On the contrary, down scales the volume shows less distancing of an authorial voice to the proposition. Force expressions can be indicated in the following: (Biook, 2007, p.85).

- degree of intensity "e.g. slightly foolish, somewhat abruptly, greatly hindered"

- - -quantity with respect to amount "e.g. tiny concern, large shark" and extent "e.g. short while, nearby mountains."

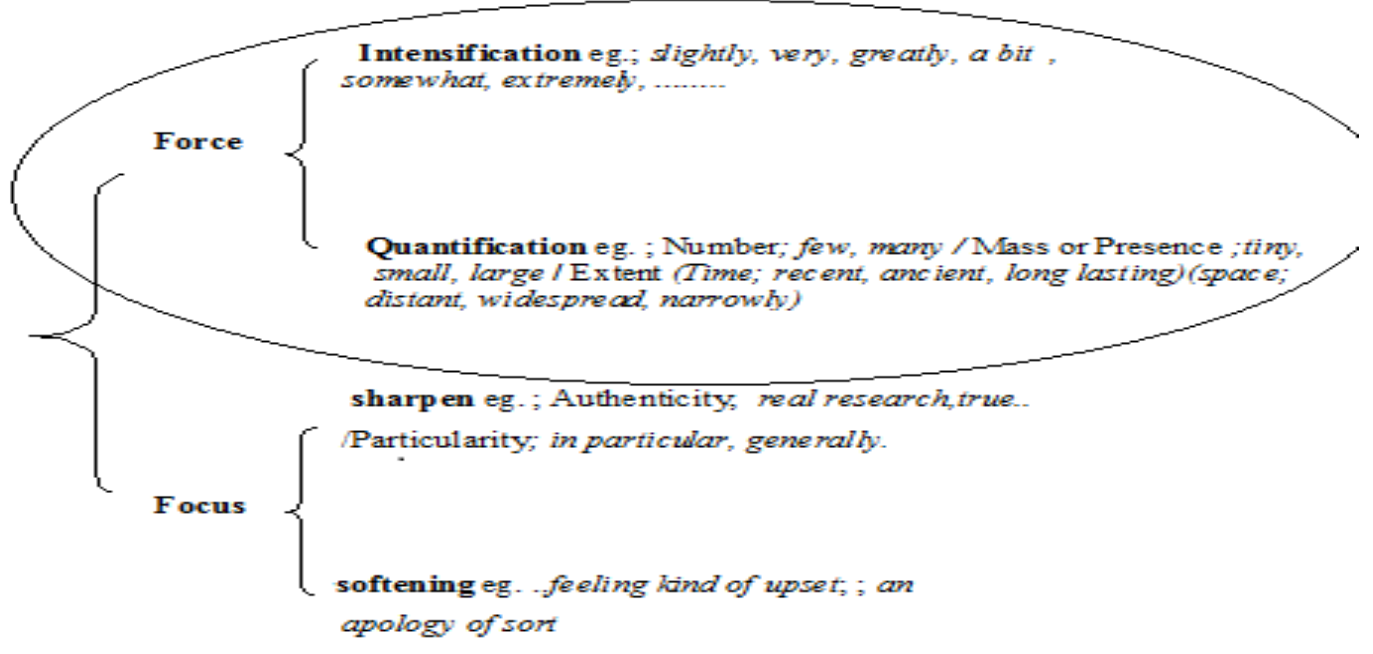

Figure 2. A preliminary outline of Graduation adopted from (Martin \&White, 2005) 


\subsection{Statement of Problem}

The main focus of this pilot study is to show how the medical authorial voice raises or lowers the utterances in the text to emphasize the degree of attachment to his/her proposition and /or not to emphasize in reference to external voices position. The investigation utilizes Martin and White (2005) Graduation subsystem of Appraisal, specifically the Force. White (2001) defined Force as "values by which speakers raise or lower the interpersonal impact or force of their utterances"(White, 2001p.2).

The point of departure in this study is to express the notion of Force in the proposition that allow writers to adjust "subtly" the presented feelings and evaluations "(Issac, 2012, p.16). Hence, in this study the aim is to explore the linguistic realizations which allow degrees of intensity and preciseness in the text such as; "intensifiers, emphasizes, and measures" that allow adjustment to the values being proposed.

Literature is not very rich in tackling these values individually or collectively, specifically in the Malaysian linguistic studies as to Graduation of appraisal in general and medical written discourse in particular and more precisely to the MCR. In this sense this study will fill a gap in linguistic literature by adding a new study to appraisal and medical studies. This pilot study is limited to investigating the communicative values of Graduation in terms of Force in medical writers' utterances, and demonstrating how they function and are distributed in written medical discourse represented by specific medical genre, that is, MCR.

\subsection{Research questions and objectives}

The current study is designed with two aims in mind:

Investigating the interpersonal values that act to provide grading or scaling in terms of Force in the MCR written in English by NNS and NS medical writers that allow attachment to the proposition.

Demonstrating the differences in providing these interpersonal values of Force utterances in the MCRs written in English by NS and NNS medical writers.

To achieve these objectives, the study intends to answer the following questions:

-What are the dominant expressions of Force in the MCRs written in English by NS and NS medical writers?

-What are the differences in employing Force expressions in the MCRs of NS and NNS medical writers?

\section{Methodology}

\subsection{Data Collection Procedure}

For the purpose of this pilot study, a comprehensive list of MCR are collected from two NS and NNS medical journals, a total of twenty MCR texts, 10 for each group of writers. These texts are published in two medical journals; "Malaysian Family Physician (FMS)" and "American Journal of Case Reports (AJMCR)." Journals' selection is depended on their representativeness, reputation, accessibility, and according to their relaion to the branch "Family Medicine." Additionally, these journals offer open-access to medical texts, which can be freely downloaded from their websites.

Malaysian Family Physician is the official journal of the Academy of Family Physicians of Malaysia (FMS), founded in 1985, published three times a year, and distributed freely to all members of the Academy of Family Physicians of Malaysia. This journal welcomes articles on all aspects of Family Medicine in the form of original research papers, review articles, case reports, brief abstracts of articles published in other journals, book reviews, and others.

All texts of NNS in this study are MCRs written by Malaysian authors. The focus in selecting the texts was on the writers' affiliation to one of the Malaysian hospitals and institutions. Nativness is not ignored completely but because Malaysia is multi-nationalities country; Malay, Chinese, and Indian authors are taken in consideration but of course exclusively to their affiliation to Malaysian hospitals and institutions.

\subsection{Medical Case Reports in NS journals}

NS medical journals especially the prestigious, with high reputation and of high impact factor are not often published MCR as NNS journals do. It is very difficult to find MCR written by NS in journals related to Family Medicine or other branches of medicine. In literature, this is due to its low economic value and authorships "MCRs are often perceived as a low-budget form of publication for fledgling medical writers"(Protopapas \& Athanasiou,2011,p.164). In fact, in spite of its lower status in comparison with MRA, MCR is considered as a stepping stone for further trials and research and has significance pedagogic and pathologic values. Consequently, one can consider these features as motivating, and encouraging elements for investigation and inquiry. Vandenbroucke (1999) illustrated the nature of MCR as a clinical trial in the era of evidence-based health care "A case report teaches us what is 'un-known' or 'un-recognized', either what medicine does not know yet ('progress'), or what individual doctors have not yet recognized ('education'). Almost always there is "the element of surprise" (Vandenbroucke, 1999, pp.159-160).

By the time, MCR turned to be a slowly disappearing genre in medical journals. In fact, today very few leading medical journals publish them. What is more, the voice of the MCR author is considered as a practitioner rather than that of a knowledge holder. This is, of course, does not imply that the authors of MCR cannot, in the situational context of other genres, play the role of experts. It only means that in the context of a MCR, they do not act as if they have the last word on a given medical issue. In other words, MCRs simply present and discuss in a "short-story-like fashion" one or few 
cases as a topic of interest to the scientific community to focus mainly on their "unusualness" for their educational values (Salager-Myer, 2001,p.77).

Fortunately, choosing the "American Journal of Case Reports" to collect MCR of NS was very convenient to help easily finding MCRs that are related to the "Family Medicine". This journal offers a very simple and helpful way for nonspecialists to identify at least the wide area of the medicine field, before asking the specialist advice. In the "Archival Case Reports" of this journal a left key helps to search specific topics like diagnoses, treatments, diseases, drug reactions, and so on. This might be very helpful to some extent in choosing MCRs of NS before a decision can be made to ask specialists to what branch of medicine these MCRs are related.

Finally, while collecting the MCRs from this journal it might be worth to mention here that MCRs written by NNS writers are more than those written by NS writers. If we consider the surname and affiliation's criterion, a large number of those writers are, in fact, mainly Asian, and non-native European rather than Natives. For example in Volume 15, 2014, which contains about 100 MCRs, most of the writers are Asian medical writers affiliated to Asian medical institutions, then European medical writers, followed by Arabs and Natives, whereas the less is related to other nationalities such as Brazilians. An important note has to be pointed out here that in the data selection of NS medical writers, the focus is on the first author surname and his/her affiliation. Many MCRs are ignored although the medical writers affiliate to native medical institutions since the surname is doubted to be NNS.

\subsection{Data Analysis Procedure}

The texts' analysis comprises many steps starting with selecting the MCRs of NS and NNS medical writers. Having selected these texts from the two medical journals, each MCR is broken down into its three main sections (Introduction, Case Report, and Discussion). Each section of these three is downed in a plane document and the same is done for NNS medical writers. Consequently, the three sections are now separated from their origins and all figures, tables, pictures, graphs, and other unwanted materials are excluded since they are not included in the analysis.

The second step is codifying Graduation incidents according to Martin \& White (2005) main classification by reading the texts manually. This step is very important in the piloting process since the first cut through the text allows to assign the expressions under investigation used in the MCR three sections and of course their synonyms with the help of dictionaries. Table (1) and (2) show the number of Force: Graduation incidents in the MCR for NS and NNS medical writers sequentially.

Figure (3) shows the distribution of Force: Graduation resources in terms of Quantification and Intensification. According to Martin \& White (2005) quantification graded two values of amount (eg size, weight, strength, number), and extent in terms of time and scope, which covers two values; proximity (ie how near, how recent) and distribution (ie how widely distributed, how long lasting) (Martin \& White, 2005, p.148-149).

\section{Results of Analysis}

\subsection{Graduation in NS Texts}

The analysis of graduation: Force is conducted according to the distribution of values indicated in Figure (3), which is adopted from Martin \& White (2005). The figure shows the distribution of Force incidents in terms of quantification and intensification in the MCR of medical writers.

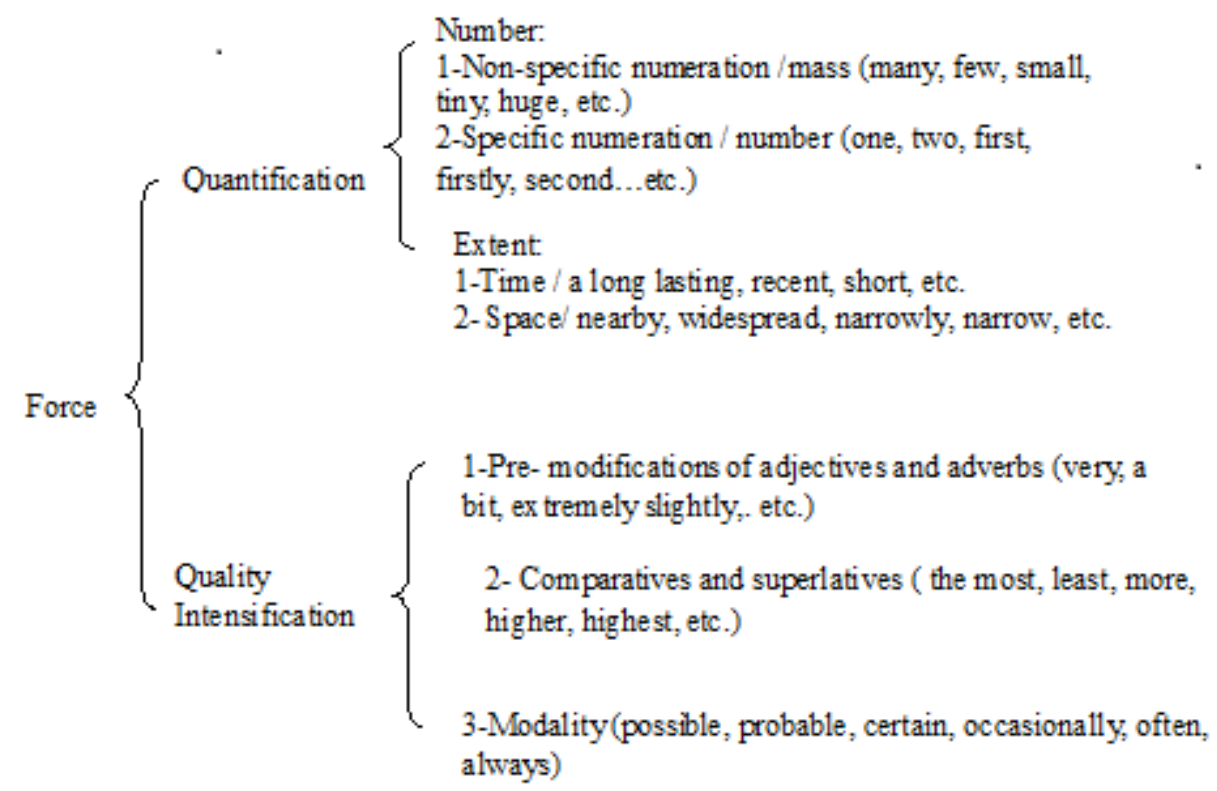

Figure 3. The Force subcategory of Graduation Subsystem (adopted from Martin \& White (2005).

Table 1 presents the observed Graduation: Force resources in the three sections of the MCRs written in English by the first group NS medical writers and their frequencies of occurrence with reference to the total number in each section. As illustrated in the table the great deal of Force incidents are indicated in the discussion sections, in addition to the 
expand of these values as quantitative incidents in all sections of the MCRs. The less occurrence of Force incidents appear in the introductions in the intensification- comparison degrees and modality. The following are some examples taken from the NS texts to illustrate the values of Graduation: Force in terms of quantification and intensification.

Table 1. Incidents of Force: Graduation in NS Texts

\begin{tabular}{|c|c|c|c|c|c|c|c|}
\hline \multirow{3}{*}{$\begin{array}{l}\text { Rhetorical } \\
\text { Section }\end{array}$} & \multicolumn{3}{|c|}{ Quantification } & \multicolumn{3}{|c|}{ Intensification } & \multirow{3}{*}{ Total } \\
\hline & \multicolumn{2}{|c|}{ Numeration } & \multirow[t]{2}{*}{ Extent } & \multicolumn{3}{|c|}{ Quality } & \\
\hline & Specific & Nonspecific & & Pre-modifier & $\begin{array}{l}\text { Superlatives \& } \\
\text { Comparatives }\end{array}$ & modality & \\
\hline \multirow{2}{*}{ Introductions } & 8 & 9 & 6 & 3 & 3 & 4 & 33 \\
\hline & $28.57 \%$ & $32.14 \%$ & $21.42 \%$ & $10.71 \%$ & $10.71 \%$ & $14.28 \%$ & \\
\hline \multirow{2}{*}{ Case Reports } & 15 & 10 & 15 & 5 & 16 & 7 & 68 \\
\hline & $22.05 \%$ & $14.70 \%$ & $22.05 \%$ & $7.35 \%$ & $23.52 \%$ & $10.29 \%$ & \\
\hline \multirow[t]{2}{*}{ Discussions } & 14 & 17 & 22 & 17 & 4 & 13 & 87 \\
\hline & $16.09 \%$ & $19.54 \%$ & $25.28 \%$ & $19.54 \%$ & $4.59 \%$ & $14.94 \%$ & \\
\hline \multirow[t]{2}{*}{ Total } & 37 & 36 & 43 & 25 & 23 & 24 & 188 \\
\hline & $19.68 \%$ & $19.14 \%$ & $22.87 \%$ & $13.29 \%$ & $12.23 \%$ & $12.79 \%$ & \\
\hline
\end{tabular}

\subsection{Quantification}

1-"Hemophagocytic lymphohistiocytosis (HLH) is not an independent disease but rather a life-threatening clinical syndrome that occurs in many (Intensification-quantification -number) underlying conditions and in all (Intensificationquantification -number) age groups (Basnet.A, \& R. Michelle, 2014, p.432).

The previous extract is taken from the introduction section of NS text. Two incidents of Force-quantificationnonspecific numeration or "vague expressions of quantity" appear. Such incidents are used by the writers to express inadequate amount (Hood, 2004, p.87-88). Many here, for example, adds meaning of relation in consequence that tends to up-scale the number, and indicates more emphasis to the proposition. Another quantification realization is the use of all which indicates also nonspecific numeration. However, all indicates a number that is relative to an entire number.

2-"The first interventional procedure in children was performed by Rashkind in 1966" (Nikhil \&Sebastian, 2014, p.278).

Incidents of specific numeration appear in the texts by referring to specific amount as ages, years, how many times, and the like. The following example is taken from the case report section of NS medical writers.

Quantification through specific number involves specific information to give more precision to the proposition. The first incident of topics' priorities is the using of "The first' which is used to prioritize the topic in a positive hint to the "interventional procedure" mentioned in the extract. Priorities such as "First, Firstly, Lastly, Secondly, To sum up. etc" are remarkable indications of graduation resources to show the sequence meaning of values (Nakamura, 2009, p.147).

3.3 Quality- Intensification

Another subcategory of Force is quality. This subcategory of force functions to up-scaling/down-scaling items by using modification, and modality. The following examples are taken from the NS texts which illustrate the manipulating features of these resources:

3-"The sagital suture was clearly (intensification pre-modifier) visible, as well as a $4 \mathrm{~mm}$ skull defect in the left frontal bone" (Daniel I. Kim, 2013, p.285).

Incident of force in terms of quality via pre-modification of adjectives and adverbs appears in the extract above that is taken from the introductions of a NS text. The pre-modification of an adjective "clearly" implies a high possible intensity that is to construe the up-scaling tone. Quality pre-modifications examples of adjectives and adverbs are "somewhat miserable, relatively miserable, fairly abruptly, very abruptly..etc.", and for modality are " quite possible, very often...etc."

4-Additionally, while it is acknowledged that MRI is usually (intensification- modality) abnormal in ADEM (Aaron \& Raymond, 2014, p.373).

The above example illustrates Force quality via maximization in terms of "usuality" "modalization" (always' usually, occasionally..etc). "Maximizes" construe the highest degree of intensity and function to convey a strong writer/interlocutors relationship investment in the proposition.

5- "In a patient with a history of breast cancer, the most common lesion in the brain is a metastasis (intensificationsuperlative)"(Daniel I. Kim, 2013, p.286)

The statement above is taken from the NS discussions section. Scaling intensity localized via using comparatives and superlatives expressions like" less, least, more, most, adjectives +er or +est like; greater, greatest etc). In example 3 a superlative incident of quality-intensification- superlative appears. Superlative and comparative incidents function to up-scale the intensity of utterance in the statement, and in return it arise the intensity of authorial voice attachment to the text.

3.3 Graduation in NNS Texts

Table (2) shows the number and frequency occurrence of Force: Graduation incidents in NNS texts. It is clear that incidents of quantitative also occupied the highly occurrence with reference to intensification. From this table one can notice that the most distribution of quantitative hits appears in the discussion sections with much focus on nonspecific numeration in the introductions and the discussions sections than the case reports sections. The following examples illustrate the distribution of these values in NNS texts. 
Table 2 Incidents of Force: Graduation in NNS Texts

\begin{tabular}{|c|c|c|c|c|c|c|c|}
\hline \multirow{3}{*}{$\begin{array}{l}\text { Rhetorical } \\
\text { Section }\end{array}$} & \multicolumn{3}{|c|}{ Quantification } & \multicolumn{3}{|c|}{ Intensification } & \multirow{3}{*}{ Total } \\
\hline & \multicolumn{2}{|c|}{ Numeration } & \multirow[t]{2}{*}{ Extent } & \multicolumn{3}{|l|}{ Quality } & \\
\hline & Specific & Nonspecific & & $\begin{array}{l}\text { Pre- } \\
\text { modifier }\end{array}$ & $\begin{array}{l}\text { Superlatives } \\
\& \\
\text { Comparatives }\end{array}$ & modality & \\
\hline Introductions & - & $\begin{array}{l}8 \\
42.10 \%\end{array}$ & $\begin{array}{l}6 \\
31.57 \%\end{array}$ & $\begin{array}{l}5 \\
26.31 \%\end{array}$ & - & - & 19 \\
\hline Case Reports & $\begin{array}{l}10 \\
29.41 \%\end{array}$ & $\begin{array}{l}2 \\
5.88 \%\end{array}$ & $\begin{array}{l}15 \\
44.11 \%\end{array}$ & $\begin{array}{l}3 \\
8.82 \%\end{array}$ & $\begin{array}{l}1 \\
2.94 \%\end{array}$ & $\begin{array}{l}3 \\
8.82 \%\end{array}$ & 34 \\
\hline Discussions & $\begin{array}{l}10 \\
14.28 \%\end{array}$ & $\begin{array}{l}13 \\
18.57 \%\end{array}$ & $\begin{array}{l}16 \\
22.85 \%\end{array}$ & $\begin{array}{l}14 \\
20 \%\end{array}$ & $\begin{array}{l}6 \\
8.57 \%\end{array}$ & $\begin{array}{l}11 \\
15.71 \%\end{array}$ & 70 \\
\hline Total & $\begin{array}{l}20 \\
16.26 \%\end{array}$ & $\begin{array}{l}23 \\
18.69 \%\end{array}$ & $\begin{array}{l}37 \\
30.08 \%\end{array}$ & $\begin{array}{l}22 \\
17.88 \%\end{array}$ & $\begin{array}{l}7 \\
5.64 \%\end{array}$ & $\begin{array}{l}14 \\
11.38 \%\end{array}$ & 123 \\
\hline
\end{tabular}

\subsection{Quantification-Numeration}

1-"Although sodium valproate associated pancreatitis cases are rare, it has been reported since 1979 with some fatal cases reported through the years (Ali MF, Loh KY, 2013, p.28)

The above extract is taken from the introduction section of an NNS text. Multiple incidents of non-specific and specific numeration are indicated, rare, for example, indicates a limited quantification scope of the number of cases follows by specific number referring to specific time 1979 to indicate preciseness. Finally, another nonspecific amount of numeration is indicated in reference to some fatal cases and years. Force in terms of quantification- unspecific numeration tends to up-scale and put emphasis the proposition.

\subsection{Quality- Intensification}

2-"Its advantages include painless examination, non-invasiveness, lack of ionising radiation, lower cost compared to MRI, dynamic imaging capability and more importantly it gives rapid interpretation..."(Ong SG, 2013, p.32)

Two incidents of quality -intensification appear in the above extract taken from NNS discussion sections. The first one involves a formulation of comparative and the second one is a per-modifier of adverb. These two formulations tend to scale-up the intensity of the statement and in consequence emphasis of a given idea . "More" here plays the role of premodifier; however in the following example taken from the case report section of a NNS text "more" indicates Intensification-quality-comparative:

3 -"His total white cell count $($ WCC) was/ $109 \times 20.7 \mathrm{~L}$ with a neutrophilic picture $(77 \% / 109 \times 15.9)(\mathrm{L})$ and the serum amylase level was 1283U/L, which was more than 10 times the normal value"(Ali MF, Loh KY,2013,p.28).

As revealed through the Force: Graduation analysis in this pilot test shows that most incidents in MCRs of both writers are concentrating on the quantification category, specifically the extent subcategory. Both groups of writers tend to scaling up or down their utterances by using quantification values of numeration and extent. White (1998) indicated that: "Measure can be understood as the application of scales of intensity to various modes of counting, and hence as its interpersonalisation - to assess some quantity as large or small is to relativise the utterance and therefore to foreground the role of the speaker's subjectivity" (White, 1998,p. 158).

Table 3. Examples of Force: Graduation incidents in the MCRs of NS and NNS medical writers and their linguistic realizations

\begin{tabular}{|c|c|c|}
\hline Reference & Text's Coded & $\begin{array}{l}\text { Linguistic Realization } \\
\text { Of Graduation- Force }\end{array}$ \\
\hline $\begin{array}{l}\text { Azidah AK,et } \\
\text { al.,2013,p.59 }\end{array}$ & $\begin{array}{l}\text { Only a small tubular soft tissue was seen posterior to } \\
\text { the urinary bladder suggestive of underdeveloped } \\
\text { Mullerian duct. }\end{array}$ & $\begin{array}{l}\text { Quantification-Non-specific } \\
\text { size }\end{array}$ \\
\hline $\begin{array}{l}\text { David Morley,et } \\
\text { al,2013,p.9 }\end{array}$ & $\begin{array}{l}\text { Extracorporeal membranous oxygenation (ECMO) is } \\
\text { the most effective rewarming method for patients } \\
\text { who suffer from severe accidental hypothermia. }\end{array}$ & $\begin{array}{l}\text { Intensification-Quality- } \\
\text { superlative }\end{array}$ \\
\hline $\begin{array}{l}\text { Yaroko AA, Mohamad I, } \\
\text { Hashim HZ,2014,p.31 }\end{array}$ & $\begin{array}{l}\text { Most commonly, the forgotten foreign body will } \\
\text { remain in the nose until patient becomes aware of the } \\
\text { foul-smelling unilateral nasal discharge. }\end{array}$ & $\begin{array}{l}\text { Intensification-Quality-adverb's } \\
\text { pre-modification }\end{array}$ \\
\hline Marion Cole, 2014, p.297 & $\begin{array}{l}\text { Unlike cPNETs, pPNETs express large amounts of } \\
\text { MIC2 antigen (CD99) and the chromosomal } \\
\text { translocation of the EWS gene with transcription } \\
\text { factors. }\end{array}$ & $\begin{array}{l}\text { Quantification-non-specific- } \\
\text { amount }\end{array}$ \\
\hline
\end{tabular}




\begin{tabular}{ll}
\hline Lisa Aimee \& Seyed- & The highest level of hypercalcemia associated \\
Ali,2014,p.295 & with rhabdomyolysis was $20 \mathrm{mg} / \mathrm{dL}[22]$. There have \\
& only been 5 other cases of hypercalcemia with serum \\
& calcium level $>15 \mathrm{mg} / \mathrm{dL}$ in the past 40 years
\end{tabular}

Mohamad I \& Kosha MY, 2013,p.41

Daniel I., et al Kim,2013, p.286
A patient may not notice hearing impairment because it may only be a slight reduction ,superimposed with long-standing sensorineura.

The majority of patients are women, with onset usually during adolescence to late 30 's.
1-Intensification-Quality-

superlative

2- Quantification-specificnumeration

3- Quantification-specificscope

1-Intensification - adjectives pre modification.

2-Quantification-specificnumeration

1-Quantification-specificamount

2-Intensification- qualitymaximization

3-Quantification-specificnumeration.

\section{Results Discussion}

The following section includes the discussion of the results obtained from the analysis of Force: Graduation in 20 MCR selected from two medical journals and written by NS and NNS medical writers who use English as a medium of writing. The discussion is presented to answer the two questions of the pilot test.

Following are the observations of the Force incidents listed in table (1) and table (2) in the three sections of MCR. The two tables indicate a predominant of quantification resources in the MCRs of the two groups of writers. The most dominant appears in the extent category $(22.8 \%)$. Frequent occurrence from the total number of force incidents in NS medical texts, and (30.08\%) of the extent incidents appear in NNS medical texts. This reveals that both writers benefit from extent strategy to show the scope and time of the statements.

'Force' values play an important role in medical discourse. The choices are set towards certain areas of the force values in terms of specific- numeration. However, in spite of their less appearance in the texts, the results indicate slight differences in adopting intensification values by the two groups of medical writers. Quantification choices of the digital measures of size, amount, and extent are gradable. They allow a cline variation in the level of analysis operating as more intensely. Table (3) introduces some examples taken from MCRs of the two groups of writers and their linguistic realizations.

The results of analysis show that both groups of writers tend to use both strategies of force. By comparing the results one can recognize that there is a kind of balance in using these resources, for example, the least incidents of intensification- modality and degrees of comparison frequent occurrence as to both writers in the introduction section. No incident in the introduction section $(0 \%)$ for NNS writers, and also less occurrence in NS with respect to other strategies $(10.71 \%)$ and $(14.28 \%)$ from the total incidents occurrence in this section sequentially.

This is also might be true if we consider the highest frequent occurrence of Force-intensification incidents in the medical texts. The occurrence of pre-modifications of adjectives and adverbs appears to be the highest among other incidents. For both medical writers the highest frequent occurrence of these incidents is in the discussion sections $19.54 \%$ for NS medical writers and $20 \%$ for NNS medical writers.

According to (M.Chatterjee, 2011) Force - quantification dimensions are used as "ploy persuasive" to align the writer with the information that commonly accepted (M.Chatterjee, 2011, p.213). They "provide further semantic clues as to how authority is established in the texts" By using the quantification mood the writer tends either to persuade reader by using nonspecific numeration as for example (many studies) as other studies are held in this area or to limit the idea by using specific numeration (only one study), hence to show particular authority position in the text (ibid, p.91).

Table 4. The overall distribution of Force: Graduation expressions in the MCRs of NS and NNS medical writers

\begin{tabular}{lllll}
\hline Rhetorical Section & \multicolumn{2}{c}{ Quantification } & Intensification & NNS \\
\cline { 2 - 5 } Introductions & NS & NNS & NS & 5 \\
& 23 & 14 & 10 & $2.15 \%$ \\
Case studies & $26.68 \%$ & $11.2 \%$ & $7.2 \%$ & 7 \\
Discussions & 40 & 27 & 28 & $3.01 \%$ \\
& $46.6 \%$ & $21.6 \%$ & $20.16 \%$ & 31 \\
Total & 53 & 39 & 34 & $13.33 \%$ \\
\hline
\end{tabular}




\section{Conclusion}

As described in this pilot test Force Graduation modulates gradable expressions in terms of Intensification of quality and Quantification of things. The two communicative strategies indicate the authorial voice degree of attachment to the proposition. In this pilot test more comprehensive accounts of the Force resources including sub-modification, modality, and degrees of comparison, extent in terms of amount and scope, and numeration in terms of specific and non-specific numbers have been illustrated.

The results of this pilot study indicate a balance in using these resources between the two groups of writers, although it is clear from Table (4) that NS medical writers are more able to use these resources especially in all the sections. The table indicates more frequency of using these resources in the MCRs of NS medical writers than that of NNS medical writers. What is more, the use of these resources in the discussion sections of both groups are higher than these distributed in the other sections.

Finally, as aforementioned the Graduation subsystem works simultaneously with the two other subsystems of Appraisal: the Attitude and Engagement. All the studies up to this moment are focusing on grading Attitude or Engagement resources. However, one available study by (Vian Jr., Orlando, 2008) was conducted to find out the resources of Graduation in the Brazilian Portuguese, by focusing on one of the narratives. However, Orlando suggested a broader discussion to all resources of Appraisal available in Portuguese.

\section{References}

Aitken, Leanne M. and Andrea P. Marshall (2007). Writing a case study: ensuring a meaningful contribution to the literature. Australian Critical Care, 20, 132-136.

Biook B,(2012) . A Comparative Genre Analysis of Hedging Expressions in Research Articles: Is Fuzziness Forever Wicked? The Southeast Asian Journal of English Language Studies, 18(2), 119 - 128.

Chang, M. (2011). Taking an effective authorial stance in academic writing: Making the linguistic resources explicit for L2 writers in the social sciences. Journal of English for Academic Purposes, 10(3),140-151

Isaac, C. (2012). Stance and Reader Positioning in Upper-Level Student Writing in Political Theory and Economics. Unpublished doctorial dissertation, The University of Michigan

Lee, S. H. (2006). The use of interpersonal resources in argumentative/persuasive essays by East-Asian ESL and Australian tertiary students. Unpublished doctorial dissertation,University of Sydney, Sydney.

Martin,\& White, (2005). The language of evaluation: Appraisal in English. London and New York: Palgrave/Macmillan.

Chatterjee,M.(2011) . Identity and textual engagement : experiences of three international students writing a doctoral thesis in EAL. Unpublished doctorial dissertation, University of Wollongong.

Nakamura,A.(2009). Construction of evaluative meanings in the IELTS writing: an intersubjective and intertextual perspective. Unpublished doctorial dissertation: University of Wollonong.

Salager-Meyer,F. (2001). From Self-Highlightedness to Self-Effacement:A Genre-Based Study of the Socio-Pragmatic Function of Criticism in Medical Discourse. LSP\& Professional Communication, 1 (2): 63-84

White, P.R.R. (2001). Introductory Guide to Appraisal. www.grammatics.com/appraisal (accessed 21-12-2012).

Vandenbroucke, J.P. (1999). Case Reports in an Evidence-based World. Journal of the Royal Society of Medicine. 92(4):159-163.

Vian Jr., Orlando (2008). Appraisal System in Brazilian Portuguese: Resources for Graduation. Odense Working Papers in Language and Communication, 29,808-824. 